\title{
Opioids and antidepressants: which combinations to avoid
}

\section{SUMMARY}

Some opioids such as tramadol, pethidine, dextromethorphan and tapentadol increase serotonergic activity. Fentanyl and methadone also do this but to a lesser extent.

These opioids may increase the risk of serotonin toxicity when combined with antidepressants.

Some selective serotonin reuptake inhibitors block the metabolism of opioids. This may reduce the concentrations and analgesic effect of some opioids such as codeine and tramadol, and increase the concentrations and risk of adverse effects of other opioids such as methadone.

Fluoxetine and irreversible monoamine oxidase inhibitors - tranylcypromine and phenelzine have prolonged actions and may interact for weeks after they have been discontinued.

\section{Introduction}

Opioid dispensing increased fourfold in Australia from 1990 to 2014 and prescribing of antidepressants doubled from 2000 to 2016 . The prescribing of both classes in combination is therefore increasingly common.,2 While many combinations have minimal risk, some may increase the risk of serotonergic effects and other toxicity, or reduce analgesic efficacy. The simplest preventive strategy is to generally avoid prescribing opioids associated with higher risks of interaction.

\section{Opioids and serotonergic activity}

The analgesic effect of opioids is mediated through three major opioid receptors - mu, delta and kappa. However, many opioids have actions on other targets, for example blocking serotonin and noradrenaline reuptake and N-methyl-aspartate (NMDA) receptors. ${ }^{3}$ This is mostly a phenomenon with synthetic opioids. These additional actions may be beneficial or harmful and occur peripherally and in the central nervous system. ${ }^{3}$

Serotonin in the neuronal synapse is tightly regulated via multiple mechanisms - a key one involves the serotonin transporter. Some opioids inhibit the serotonin transporter which increases concentrations of serotonin in the synaptic cleft and therefore postsynaptic serotonin signalling., ${ }^{4,5}$

\section{Toxicity}

Serotonin toxicity or syndrome results from excessive serotonin and its severity depends on the amount of excess serotonin. The three main groups of features are: ${ }^{6}$

- neuromuscular hyperactivity - clonus, myoclonus, tremor, hyperreflexia, rigidity
- autonomic hyperactivity - fevers, tachycardia, diaphoresis, tachypnoea

- altered mental state.

Serotonin toxicity generally only occurs when serotonergic opioids are given with another serotonergic drug such as an antidepressant, even at therapeutic doses (see Box). ${ }^{3}$ The highest risk opioid drugs are tramadol, pethidine and dextromethorphan. ${ }^{7}$ The highest risk serotonergic drugs are the irreversible monoamine oxidase inhibitor (MAOI) antidepressants, tranylcypromine and phenelzine. ${ }^{8}$ The risk and precautions with different combinations are summarised in the Table. 3,6,7,9 The highest risk for serotonin toxicity by far is with irreversible MAOIs and pethidine, tramadol or dextromethorphan.

There have been occasional case reports of serotonin toxicity with low-risk opioid and antidepressant combinations, such as oxycodone and buprenorphine/naloxone (Suboxone) with other serotonergic medicines. ${ }^{10-13}$ Many of these reports have very obvious alternative medical explanations for all the signs of the alleged severe serotonin toxicity. ${ }^{14}$ However, it also seems likely that moderate serotonin toxicity may occasionally be precipitated by any opioid in susceptible individuals taking an antidepressant, perhaps due to indirect effects of opioids on serotonin release. A high index of suspicion is therefore needed. ${ }^{8}$ Similarly, antidepressants such as agomelatine, mianserin and reboxetine have a very low risk of serotonin syndrome but caution still might be warranted in combination with very high-risk serotonergic drugs. ${ }^{3,5,7}$

\section{Varan Perananthan iD}

Clinical pharmacology and toxicology advanced trainee ${ }^{1,2}$

\section{Nicholas Buckley}

Consultant clinical pharmacologist and toxicologist ${ }^{1}$

Professor of Clinical Pharmacology²

1 Edith Collins Centre, Drug Health Services, Royal Prince Alfred Hospital, Sydney

2 School of Medical Sciences, Biomedica Informatics and Digital Health, University of Sydney

\section{Keywords}

antidepressants, drug interactions, monoamine oxidase inhibitors, opioids, serotonin toxicity

Aust Prescr 2021:44:41-4 https://doi.org/10.18773/ austprescr.2021.004 


\section{Box Drugs likely to increase the risk of serotonin toxicity when combined with serotonergic opioids ${ }^{3}$}

Monoamine oxidase inhibitors

- irreversible inhibitors (phenelzine, tranylcypromine)

- reversible inhibitors of monoamine oxidase (moclobemide)

- non-antidepressant monoamine oxidase inhibitors (linezolid, methylene blue, lamotrigine)

Serotonin-releasing drugs

- appetite suppressants (fenfluramine, sibutramine)

- amphetamines (methamphetamine, methylphenidate, phentermine)

- synthetic stimulants (MDMA, cathinones)

Serotonin reuptake inhibitors

- selective serotonin reuptake inhibitors

- serotonin noradrenaline reuptake inhibitors

- tricyclic antidepressants (clomipramine, imipramine)

- serotonin modulators (vortioxetine)

Miscellaneous

- lithium

- St John's wort

- tryptophan

- buspirone

- triptans

MDMA 3,4-methylenedioxymethamphetamine

\section{Table The risk of serotonergic toxicity with combinations of antidepressants and opioids $3,6,7,9$}

\begin{tabular}{l|l|l}
\hline \multirow{2}{*}{} & \multicolumn{2}{|c}{ Antidepressants } \\
\cline { 2 - 3 } & $\begin{array}{l}\text { Low-intermediate risk } \\
\text { SSRIs, SNRIs, TCAs, } \\
\text { St John's wort, lithium }\end{array}$ & $\begin{array}{l}\text { High risk } \\
\text { MAOIs (or previous history } \\
\text { of serotonin toxicity) }\end{array}$ \\
\hline $\begin{array}{l}\text { Low risk } \\
\begin{array}{l}\text { Morphine, codeine, } \\
\text { buprenorphine, } \\
\text { oxymorphone, } \\
\text { hydromorphone, } \\
\text { oxycodone }\end{array}\end{array}$ & $\begin{array}{l}\text { Should be safe } \\
\text { Possible rare interaction. } \\
\text { Use with caution }\end{array}$ \\
\hline $\begin{array}{l}\text { Medium risk } \\
\begin{array}{l}\text { Fentanyl, tapentadol, } \\
\text { methadone }\end{array}\end{array}$ & $\begin{array}{l}\text { Possible rare interaction. } \\
\text { Use with caution }\end{array}$ & $\begin{array}{l}\text { Increased risk of serotonin } \\
\text { syndrome }\end{array}$ \\
\hline $\begin{array}{l}\text { High risk } \\
\begin{array}{l}\text { Tramadol, }{ }^{*} \text { pethidine, } \\
\text { dextromethorphan }\end{array}\end{array}$ & $\begin{array}{l}\text { Increased risk of serotonin } \\
\text { syndrome }\end{array}$ & Contraindicated \\
\hline
\end{tabular}

* risk of decreased analgesic effect

SSRI selective serotonin reuptake inhibitor

SNRI serotonin noradrenaline reuptake inhibitor

TCA tricyclic antidepressant

MAOI monoamine oxidase inhibitor

\section{Inhibition of opioid metabolism}

The two most commonly used 'weak opioids' codeine and tramadol require cytochrome P450 (CYP) 2D6 for conversion to an active opioid agonist. They consequently have less abuse potential which allows less restrictive scheduling in most countries. However, many antidepressants are CYP2D6 inhibitors (fluoxetine, paroxetine, and to a lesser extent duloxetine, fluvoxamine, sertraline, desvenlafaxine and escitalopram). This means combinations of codeine or tramadol with these antidepressants may lead to reduced analgesia. ${ }^{15}$

Conversely, inhibition of metabolism of other opioids (via a variety of enzymes) may lead to increased risks of opioid adverse effects. The combinations that are particularly of concern are specific to individual drugs such as tramadol, tapentadol, fentanyl and methadone.

\section{Tramadol}

While tramadol's main metabolite is an opioid agonist, it is remarkably similar in structure to venlafaxine, with similar inhibitory effects on noradrenaline and serotonin reuptake. ${ }^{16,17}$ The combination of tramadol with an antidepressant is by far the most common serotonergic drug-drug interaction. 18,19

As tramadol inhibits serotonin and noradrenaline reuptake, combinations with selective serotonin reuptake inhibitors (SSRIs) or serotonin noradrenaline reuptake inhibitors (SNRIs) are likely to have additional adverse effects without added benefits. Inhibition of CYP2D6 by common antidepressants such as paroxetine and fluoxetine ${ }^{20}$ not only reduces conversion of tramadol to an opioid agonist, it also results in higher concentrations of tramadol. Thus, these antidepressants both directly and indirectly increase the serotonergic and other adverse effects of tramadol, while potentially reducing analgesic efficacy. ${ }^{16,21}$

Seizures are a key adverse effect of tramadol and can occur in overdose.22 Tramadol is also commonly implicated in new onset seizures with therapeutic use. ${ }^{23}$ This risk is further heightened when it is co-administered with SSRIs, tricyclic antidepressants, venlafaxine and bupropion..$^{21,24-26}$

\section{Tapentadol}

Tapentadol has different pharmacology to tramadol. It is an opioid agonist without active metabolites and a noradrenaline reuptake inhibitor with only weak effects on serotonin reuptake. ${ }^{27} \mathrm{MAOI}$ use is contraindicated with tapentadol and there have been many reports to regulatory agencies of serotonin toxicity with this combination. ${ }^{7}$ MAOls were also excluded from most tapentadol trials. ${ }^{9}$ Currently, it is unclear if tapentadol has a greater risk of serotonin toxicity than other opioids. 


\section{Fentanyl}

Fentanyl is a high-potency opioid agonist with no effect on serotonin reuptake and low affinity (relative to opioid receptor affinity) for postsynaptic serotonin receptors $\left(5-\mathrm{HT}_{1 \mathrm{~A}}\right.$ and $\left.5-\mathrm{HT}_{2 \mathrm{~A}}\right){ }^{5} \mathrm{Co}$-administration with an SSRI has been reported to cause an agitated delirium consistent with serotonin toxicity. ${ }^{28}$ However, in a retrospective analysis of 4583 people who received fentanyl and another serotonergic drug, only 23 of them had adverse events and only four (0.09\%) met the criteria for serotonin syndrome. ${ }^{29}$ It is also unclear how fentanyl compares to other opioids in terms of the risk of serotonin syndrome. However, its combination with an MAOI is contraindicated.

\section{Methadone}

Methadone is largely used in the management of opioid dependence. It also has potential serotonergic effects with serotonin and noradrenaline reuptake inhibition and high affinity for serotonin receptors $\left(5-\mathrm{HT}_{2 \mathrm{~A}}\right.$ and $\left.5-\mathrm{HT}_{2 \mathrm{C}}\right) \cdot{ }^{5}$ Methadone has been associated with serotonin toxicity when given with other serotonergic medicines but the risk appears low. ${ }^{7}$

Methadone also has highly variable hepatic clearance via CYP3A4, CYP2B6 and CYP2D6. Most SSRIs and SNRIs inhibit one or more of these enzymes and might then precipitate methadone toxicity. Methadone and (es)citalopram both cause QT prolongation, thus providing yet another potential interaction.

\section{Antidepressants and duration of risk}

Avoiding high-risk combinations can be difficult and this is further complicated by three factors:

- many antidepressants have prolonged durations of action so patients may be at risk of interactions for two weeks after an irreversible MAOI is discontinued and five weeks after fluoxetine is discontinued ${ }^{4,6,7}$

- sudden cessation of short-acting antidepressants commonly causes withdrawal phenomena, which might even be misinterpreted as serotonin toxicity

- there are high rates of substance dependence and concomitant depression.

\section{Other drug interactions}

Sedating antidepressants such as tricyclics, tetracylics (mirtazepine and mianserin) and agomelatine in combination with opioids can exacerbate drowsiness which can increase the risk of falls and respiratory depression. ${ }^{30}$

Serotonergic drug interactions are not confined to antidepressants and opioids. For example, very severe interactions may occur with methylene blue and linezolid which inhibit monoamine oxidase and care should be taken when these are prescribed with opioids or antidepressants.

The combination of an opioid and drugs with anticholinergic effects can increase the risk of constipation, urinary retention and delirium.

\section{Conclusion}

Co-administration of antidepressants and opioids, deliberate or unplanned, is common. The risk of serotonin toxicity should be evaluated routinely but by far the highest risk is with MAOIs and pethidine, tramadol or dextromethorphan. Avoiding the routine use of any of these higher risk drugs is the simplest prescribing strategy. If there is an urgent need for opioids in someone taking an MAOI, using a nonsynthetic opioid like morphine is preferred.

There are many kinetic interactions, adverse effects and withdrawal phenomena from all of these drugs. Clinicians should not assume that problems from combining these drugs can be explained by serotonin toxicity, and other obvious alternative medical explanations should also be considered. $<$

\section{Conflicts of interest: none declared}

\section{REFERENCES}

1. Karanges EA, Blanch B, Buckley NA, Pearson SA. Twentyfive years of prescription opioid use in Australia: a wholeof-population analysis using pharmaceutical claims. Br J Clin Pharmacol 2016;82:255-67. https://doi.org/10.1111/ bcp.12937

2. Davey CG, Chanen AM. The unfulfilled promise of the antidepressant medications. Med J Aust 2016;204:348-50. https://doi.org/10.5694/mja16.00194

3. Buckley NA, Dawson AH, Isbister GK. Serotonin syndrome. BMJ 2014;348:g1626. https://doi.org/10.1136/bmj.g1626

4. Baldo BA. Opioid analgesic drugs and serotonin toxicity (syndrome): mechanisms, animal models, and links to clinical effects. Arch Toxicol 2018;92:2457-73. https://doi.org/10.1007/ s00204-018-2244-6
5. Rickli A, Liakoni E, Hoener MC, Liechti ME. Opioid-induced inhibition of the human 5-HT and noradrenaline transporters in vitro: link to clinical reports of serotonin syndrome. Br J Pharmacol 2018;175:532-43. https://doi.org/10.1111/ bph.14105

6. Isbister GK, Buckley NA, Whyte IM. Serotonin toxicity: a practical approach to diagnosis and treatment. Med J Aust 2007;187:361-5. https://doi.org/10.5694/ .1326-5377.2007.tb01282.x

7. Baldo BA, Rose MA. The anaesthetist, opioid analgesic drugs, and serotonin toxicity: a mechanistic and clinical review. Br J Anaesth 2020;124:44-62. https://doi.org/ 10.1016/j.bja.2019.08.010 
8. Gillman PK. Monoamine oxidase inhibitors, opioid analgesics and serotonin toxicity. Br J Anaesth 2005;95:434-41. https://doi.org/10.1093/bja/aei210

9. Gressler LE, Hammond DA, Painter JT. Serotonin syndrome in tapentadol literature: systematic review of original research. J Pain Palliat Care Pharmacother 2017;31:228-36. https://doi.org/10.1080/15360288.2017.1416440

10. Karunatilake H, Buckley NA. Serotonin syndrome induced by fluvoxamine and oxycodone. Ann Pharmacother 2006;40:155-7. https://doi.org/10.1345/aph.1E671

11. Isenberg D, Wong SC, Curtis JA. Serotonin syndrome triggered by a single dose of suboxone. Am J Emerg Med 2008;26:840.e3-5. https://doi.org/10.1016/j.ajem.2008.01.039

12. Rosebraugh CJ, Flockhart DA, Yasuda SU, Woosley RL. Visual hallucination and tremor induced by sertraline and oxycodone in a bone marrow transplant patient. J Clin Pharmacol 2001;41:224-7. https://doi.org/10.1177/ 00912700122009926

13. Walter C, Ball D, Duffy M, Mellor JD. An unusual case of serotonin syndrome with oxycodone and citalopram. Case Rep Oncol Med 2012;2012:261787. https://doi.org/ $10.1155 / 2012 / 261787$

14. John S, Donnelly M, Uchino K. Catastrophic reversible cerebral vasoconstriction syndrome associated with serotonin syndrome. Headache 2013;53:1482-7. https://doi.org/10.1111/head.12202

15. Frost DA, Soric MM, Kaiser R, Neugebauer RE. Efficacy of tramadol for pain management in patients receiving strong cytochrome P450 2D6 inhibitors. Pharmacotherapy 2019;39:724-9. https://doi.org/10.1002/phar.2269

16. Grond S, Sablotzki A. Clinical pharmacology of tramadol. Clin Pharmacokinet 2004;43:879-923. https://doi.org/ 10.2165/00003088-200443130-00004

17. Katz WA. Pharmacology and clinical experience with tramadol in osteoarthritis. Drugs 1996;52 Suppl 3:39-47. https://doi.org/10.2165/00003495-199600523-00007

18. Ringland C, Mant A, McGettigan P, Mitchell P, Kelman C, Buckley $\mathrm{N}$, et al. Uncovering the potential risk of serotonin toxicity in Australian veterans using pharmaceutical claims data. Br J Clin Pharmacol 2008;66:682-8. https://doi.org/ 10.1111/j.1365-2125.2008.03253.x

19. Shatin D, Gardner JS, Stergachis A, Blough D, Graham D. Impact of mailed warning to prescribers on the co-prescription of tramadol and antidepressants. Pharmacoepidemiol Drug Saf 2005;14:149-54. https://doi.org/10.1002/pds.961
20. Beakley BD, Kaye AM, Kaye AD. Tramadol, pharmacology, side effects, and serotonin syndrome: a review. Pain Physician 2015;18:395-400.

21. Park SH, Wackernah RC, Stimmel GL. Serotonin syndrome: is it a reason to avoid the use of tramadol with antidepressants? J Pharm Pract 2014;27:71-8. https://doi.org/ 10.1177/0897190013504957

22. Ryan NM, Isbister GK. Tramadol overdose causes seizures and respiratory depression but serotonin toxicity appears unlikely. Clin Toxicol (Phila) 2015;53:545-50. https://doi.org/ 10.3109/15563650.2015.1036279

23. Labate A, Newton MR, Vernon GM, Berkovic SF. Tramadol and new-onset seizures. Med J Aust 2005;182:42-3. https://doi.org/10.5694/j.1326-5377.2005.tb06556.x

24. Ripple MG, Pestaner JP, Levine BS, Smialek JE. Lethal combination of tramadol and multiple drugs affecting serotonin. Am J Forensic Med Pathol 2000;21:370-4. https://doi.org/10.1097/00000433-200012000-00015

25. Daubin C, Quentin C, Goullé JP, Guillotin D, Lehoux P, Lepage $\mathrm{O}$, et al. Refractory shock and asystole related to tramadol overdose. Clin Toxicol (Phila) 2007;45:961-4. https://doi.org/10.1080/15563650701438847

26. Sansone RA, Sansone LA. Tramadol: seizures, serotonin syndrome, and coadministered antidepressants. Psychiatry (Edgmont) 2009;6:17-21.

27. Raffa RB, Buschmann H, Christoph T, Eichenbaum G, Englberger W, Flores CM, et al. Mechanistic and functional differentiation of tapentadol and tramadol. Expert Opin Pharmacother 2012;13:1437-49. https://doi.org/ 10.1517/14656566.2012.696097

28. Kirschner R, Donovan JW. Serotonin syndrome precipitated by fentanyl during procedural sedation. J Emerg Med 2010;38:477-80. https://doi.org/10.1016/ j.jemermed.2008.01.003

29. Koury KM, Tsui B, Gulur P. Incidence of serotonin syndrome in patients treated with fentanyl on serotonergic agents. Pain Physician 2015;18:E27-30. https://pubmed.ncbi.nlm.nih.gov/25675067/

30. Wahab MS, Nyfort-Hansen K, Kowalski SR. Inappropriate prescribing in hospitalised Australian elderly as determined by the STOPP criteria. Int J Clin Pharm 2012;34:855-62. https://doi.org/10.1007/s11096-012-9681-8 